\title{
ANÁLISE DA PERCEPÇÃO AMBIENTAL PARA GRUPOS DE FAIXAS ETÁRIAS DISTINTAS
}

\author{
Raul Selverio Fuso ${ }^{1}$
}

Carolina Julian $^{2}$

\section{Renata Ribeiro de Araujo ${ }^{3}$}

\begin{abstract}
RESUMO
A presente pesquisa objetivou identificar a eficácia da utilização de métodos teóricos e práticos para analisar a percepção ambiental de voluntários, de diferentes faixas etárias, antes e após as oficinas, que foram realizadas com a intenção de transmitir informações sobre biomonitoramento de bacias hidrográficas, explicando sua importância na determinação da qualidade dos corpos d'água e exemplificando parâmetros que foram utilizados para avaliar a qualidade destes corpos, tais como $\mathrm{pH}$, ferro, amônia, entre outros. Para analisar a percepção ambiental, questionários foram entregues aos capacitados, contendo perguntas relacionadas aos conhecimentos sobre a importância da mata ciliar e dos corpos d'água, além de seus componentes e parâmetros de qualidade. Esses questionários foram distribuídos no início da oficina, para avaliar o conhecimento prévio sobre rios que os mesmos apresentavam, e repassados ao final da parte prática. Por conterem as mesmas perguntas, foi possível a comparação das respostas e inferir o quanto de conhecimento os participantes assimilaram em relação à parte prática e teórica da oficina, possibilitando assim a realização da análise da percepção ambiental pelos dados obtidos nos questionários, notou-se que a percepção ambiental aumentou significativamente de forma clara e concisa, tanto para crianças quanto para adolescentes.
\end{abstract}

PALAVRAS-CHAVE: Percepção ambiental. Bacias hidrográficas. Oficinas.

\section{ANALYSIS OF ENVIRONMENTAL PERCEPTION FOR GROUPS OF DIFFERENTS AGES}

\footnotetext{
${ }^{1}$ Graduando em Engenharia Ambiental, UNESP. raulfuso@hotmail.com.

${ }^{2}$ Graduanda em Engenharia Ambiental, UNESP. carolina.julian@hotmail.com.

${ }^{3}$ Doutora, Faculdade de Ciências e Tecnologia - UNESP. reribeiro@fct.unesp.br.
} 


\begin{abstract}
This research aimed to identify the effectiveness of the use of theoretical and practical methods to analyze the environmental perception of volunteers of different age groups before and after the workshops, which were held with the intention of conveying information about biomonitoring watershed, explaining its importance in determining the quality of water bodies and exemplifying parameters that were used to evaluate the quality of these bodies, such as $\mathrm{pH}$, iron, ammonia, among others. To analyze the environmental perception, questionnaires were given to trained, containing questions related to knowledge about the importance of riparian vegetation and water bodies, as well as its components and quality parameters. These questionnaires were distributed at the beginning of the workshop, to assess the prior knowledge that they presented, and were repassed in the final of the practice part. To contain the same questions, it was possible to compare the answers and infer how much knowledge the participants assimilated in relation to theoretical and practical part of the workshop, thus enabling the achievement of the analysis of environmental perception by data obtained from the questionnaire, thus enabling the achievement of the analysis of environmental perception by data obtained from the questionnaire, it was noted that environmental perception has increased significantly in a clear and concise manner, both for children and teenagers.
\end{abstract}

KEY-WORDS: Environmental perception. Watershed. Workshops.

\title{
ANÁLISES DE LA PERCEPCIÓN AMBIENTAL PARA GRUPOS DE DIFERENTES EDADES
}

\begin{abstract}
RESUMEN
Esta pesquisa objetivó identificar la eficacia de la utilización de métodos teóricos y prácticos para analizar la percepción ambiental de voluntarios de diferentes edades, antes y después de los seminarios, que fueran realizaos con la intención de transmitir informaciones sobre biomonitoramento de cuencas hidrográficas, explicando su importancia en la determinación de la cualidad de estos cuerpos, como pH, hierro, amoniaco y otros. Para analizar la percepción ambiental, cuestionarios fueran entregues a los capacitados, contiendo preguntas relacionadas a los conocimientos sobre la importancia de la mata ciliar y de los cuerpos de agua, además de sus componentes y parámetros de calidad. Esos cuestionarios fueran distribuidos en el inicio del seminario, para evaluar el conocimiento previo sobre ríos que los mismos presentaban, y repasados al final de la parte práctica. Por contener las mismas preguntas, fue posible la comparación de las respuestas e inferir lo cuento de conocimiento los participantes asimilaran en relación a la parte práctica y teórica del seminario, posibilitando así la realización de la análisis de la percepción ambiental, por los datos obtenidos en los cuestionarios, se observó que la percepción ambiental aumentó significativamente de forma clara y concisa, tanto para chicos cuanto para adolescentes.
\end{abstract}

PALABRAS-CLAVE: Percepción Ambienta. Cuencas Hidrográfica. Seminario. 


\section{INTRODUÇÃO}

A atual abordagem em relação ao meio ambiente considera que os recursos naturais são finitos e, alguns até escassos. Movimentos, visando à diminuição dos impactos introduzidos pelas atividades industriais sobre o meio ambiente, vêm ganhando força desde a década de 70. (BRANDALISE et al, 2009).

Entretanto ainda é perceptível, segundo Lima (1999), uma contradição entre o modelo dominante de desenvolvimento econômico-industrial e a realidade socioambiental, onde a busca pelo desenvolvimento técnico-científico muitas vezes se sobrepõe ao meio ambiente, causando sua degradação.

Mas estes processos não podem continuar a acontecer, assim como é dito por Brandalise et al. (2009), onde os mesmos enunciam que a humanidade está acordando para a urgência e importância da questão ambiental, demonstrando que é preciso desencadear um processo contínuo de sensibilização e conscientização, o que pode ser conseguido com ações proativas, sendo que as escolas podem ser um instrumento de divulgação da educação ambiental.

Esta sensibilização pode ser entendida como sensibilização ambiental, definida por Medeiros et al. (2004) como o processo de "chamamento", de olhar numa direção antes distante do campo de motivação. É um dos primeiros momentos do processo educativo que insere o educando num mundo que se quer ver (re)descoberto, ou simplesmente notado.

A sensibilização ambiental está ligada a percepção ambiental, que segundo Melazo (2005), deve ser entendida enquanto um processo participativo, envolvendo uma série de fatores sensoriais, subjetivos e valores sociais, culturais e atitudes ambientais das comunidades residentes nas cidades em relação ao espaço natural e transformado.

Todos estes processos podem e devem ser motivados através da educação ambiental, definida por Ruscheinsky (2002) como sendo o reordenamento do meio ambiente, à valorização da cidadania e à consolidação da democracia abrangendo as dimensões sociais, política e econômica, demonstrando a relevância da educação 
ambiental no sentido de conferir uma partição ativa dos cidadãos, por meio do consentimento e do compromisso com o meio ambiente.

Segundo Dias (2001), em tempos anteriores, o Brasil não possuía uma política educacional definida, muito menos uma política para "Educação Ambiental". Entretanto, há alguns anos esta paisagem mudou, pois a Política Nacional de Educação Ambiental (Lei n 9795 de 27 de abril de 1999) foi desenvolvida, assim como uma rica listagem de literaturas especializadas nesta área.

A lei n 9795 de 27 de abril de 1999 dispõe sobre a educação ambiental, institui a Política Nacional de Educação Ambiental e dá outras providências, sendo que em seu capítulo I, art. $1^{\circ}$, exemplifica a educação ambiental como sendo os processos por meio dos quais o indivíduo e a coletividade constroem valores sociais, conhecimentos, habilidades, atitudes e competências voltadas para a conservação do meio ambiente, bem de uso comum do povo, essencial à sadia qualidade de vida e sua sustentabilidade.

Segundo a mesma Lei, em seu art. $4^{\circ}$, são listados os princípios básicos da educação ambiental, sendo o enfoque humanista, holístico, democrático e participativo, a abordagem articulada das questões ambientais locais, regionais, nacionais e globais, entre outros tópicos. Já em seu art. $5^{\circ}$ são listados os objetivos fundamentais da educação ambiental, que pode ser entendido como o desenvolvimento de uma compreensão integrada do meio ambiente em suas múltiplas e complexas relações, envolvendo aspectos ecológicos, psicológicos, legais, entre outros.

Sauvé (2005) enuncia que a educação ambiental visa a induzir dinâmicas sociais, de início na comunidade local e, posteriormente, em redes mais amplas de solidariedade, promovendo, deste modo, a abordagem colaborativa e crítica das realidades socioambientais e uma compreensão dos problemas que se apresentam e das possíveis soluções para eles.

Segundo Possamai et al. (2009), a percepção ambiental é decorrente da educação ambiental, que pode também ser entendida como um instrumento para tentar sanar ou minimizar os problemas ambientais. 
A educação ambiental é utilizada para a melhoria da qualidade dos corpos hídricos, pois, segundo Alves (2006), a água é o elemento fundamental da vida e seus múltiplos usos são de extrema importância para um largo espectro das atividades humanas.

Apesar disto, de acordo com Freire (2010), a humanidade sempre a considerou como um recurso infinito, utilizando-o de forma predatória e insustentável durante muito tempo, o que vem causando uma grande preocupação relacionada à qualidade da água que está disponível para uso.

Logo, o artigo visa à análise na melhoria da percepção ambiental entre dois grupos de faixas etárias distintas através da educação ambiental utilizando-se de questionários previamente estabelecidos relacionados a recursos hídricos, comparando as respostas obtidas em relação às faixas etárias.

\section{MATERIAL E MÉTODOS}

A presente pesquisa foi desenvolvida por meio de oficinas, realizadas no dia 04 de setembro de 2013 para 30 crianças do $6^{\circ}$ ano do Ensino Fundamental, e no dia 29 de outubro de 2013 para 24 graduandos, que tem seus estudos voltados para a área ambiental.

Através destas oficinas foi possível ensinar aos capacitados conceitos básicos em relação à qualidade e importância dos corpos d'água. Estas foram divididas em partes teóricas e práticas, sendo que a prática foi desenvolvida no Córrego do Cedro, localizado na cidade de Presidente Prudente / SP.

A parte teórica, conhecida como primeira fase, realiza-se num intervalo de tempo de acordo com a faixa etária dos capacitados, enquanto a parte prática, conhecida como segunda fase, desenvolve-se em campo, com os equipamentos necessários.

Para os capacitados mais velhos, tais como professores, proprietários rurais, entre outros se utilizou um intervalo de 4 horas. Já para capacitados mais jovens, como alunos de do ensino fundamental e médio, este tempo foi reduzido para 2 horas. 
No início da primeira fase foi passado um questionário para que se tenham dados do conhecimento prévio da percepção ambiental dos participantes, intitulado de questionário I. Apresentou-se também a localização do rio onde se realizou a parte prática, ressaltando a bacia hidrográfica a qual os capacitados estavam inseridos.

Em seguida, a metodologia para o biomonitoramento da bacia e de sua importância para determinar a qualidade ecológica dos rios foi apresentada. Foram distribuídos aos voluntários os materiais didáticos, tais como: i) manual de inspeção de rios - guia de inspeção fluvial (ora também denominada de apostila); ii) ficha índice de qualidade da mata ciliar e espécies vegetais mais comuns em nossos rios; iii) ficha de identificação dos macroinvertebrados bentônicos e guia de identificação do estado biológico; e iv) ficha de campo. A metodologia encontrou-se disponível no site do projeto Rios Vivos: http://bacias.fct.unesp.br/riosvivos/

Discutiu-se o papel da Educação Ambiental na conscientização da população sobre a necessidade de cuidar dos mananciais, fundamental para garantir a sustentabilidade do abastecimento e aumentar a disponibilidade de água nos rios.

Posteriormente deu-se início a segunda fase, cuja foi realizado o trabalho de campo, colocando-se em prática os conhecimentos previamente adquiridos, especialmente como deve ser realizada as bioanálises das águas, analisando parâmetros físico-químicos, tais como pH, ferro, amônia, entre outros, através de kits (Ecokit). Mediu-se também a vazão do córrego.

As condições ambientais da mata ciliar foram estudadas. Identificaram-se os macroinvertebrados bentônicos, através de lupas e fichas que auxiliaram na identificação das espécies encontradas, assim pode se comparar com os padrões predefinidos e determinar a qualidade da água do córrego.

Ao final da oficina foi repassado o questionário II, que continham as mesmas perguntas do questionário I, para a comparação da evolução da percepção ambiental dos participantes.

A partir dos questionários aplicados foi possível analisar uma melhora no conhecimento dos capacitados comparando as respostas obtidas nos questionários aplicados durante as oficinas. 


\section{RESULTADO E DISCUSSÃo}

Analisando as crianças, notou-se que anteriormente a parte prática, $55 \%$ nunca tinham tido contato com algum corpo d'água, e apenas $26 \%$ não sabiam o que era qualidade da água.

Ao final observou-se que o projeto proporcionou a oportunidade de todas terem um primeiro contato com um corpo d'água, apesar de $7 \%$ ainda dizerem que não tiveram, e todos passaram conhecer o que é qualidade da água.

Estes $7 \%$ podem ser explicados pelo fato de que algumas crianças não terem tido um contato direto com o corpo d'água, e terem entendido a pergunta de uma maneira direta, e não figurada.

Já com a turma de universitários, utilizando-se da mesma pergunta destacada anteriormente, percebe-se que há uma grande diferença, pois apenas $21 \%$ das pessoas não tinham tido contado com um rio e esta mesma quantidade disse não saber o que é qualidade de um rio, uma diferença não muito significativa se comparada com os alunos do $6^{\circ}$ ano.

Porém, é necessário considerar que a turma estava cursando o segundo semestre do curso e poderiam não ter tido contato com o conceito até o momento, portanto essa porcentagem é aceitável.

Ao final da parte prática, todos os universitários disseram já ter tido contato com um corpo d'água e sabiam o que era qualidade da água.

Outra questão analisada é sobre o que os capacitados acreditavam que tivesse dentro de corpos hídricos.

Analisando primeiramente as crianças, nota-se que estas, em maioria, assinalaram que há plantas, animais, substâncias químicas, microorganismos, parasitas, rochas e resíduos, sendo que 50\% respondeu que há sedimentos, como indica a figura 1. 
Figura 1: Resultados da questão 1, "O que você acha que tem nos rios?", aplicada para os alunos do 60 ano referente a

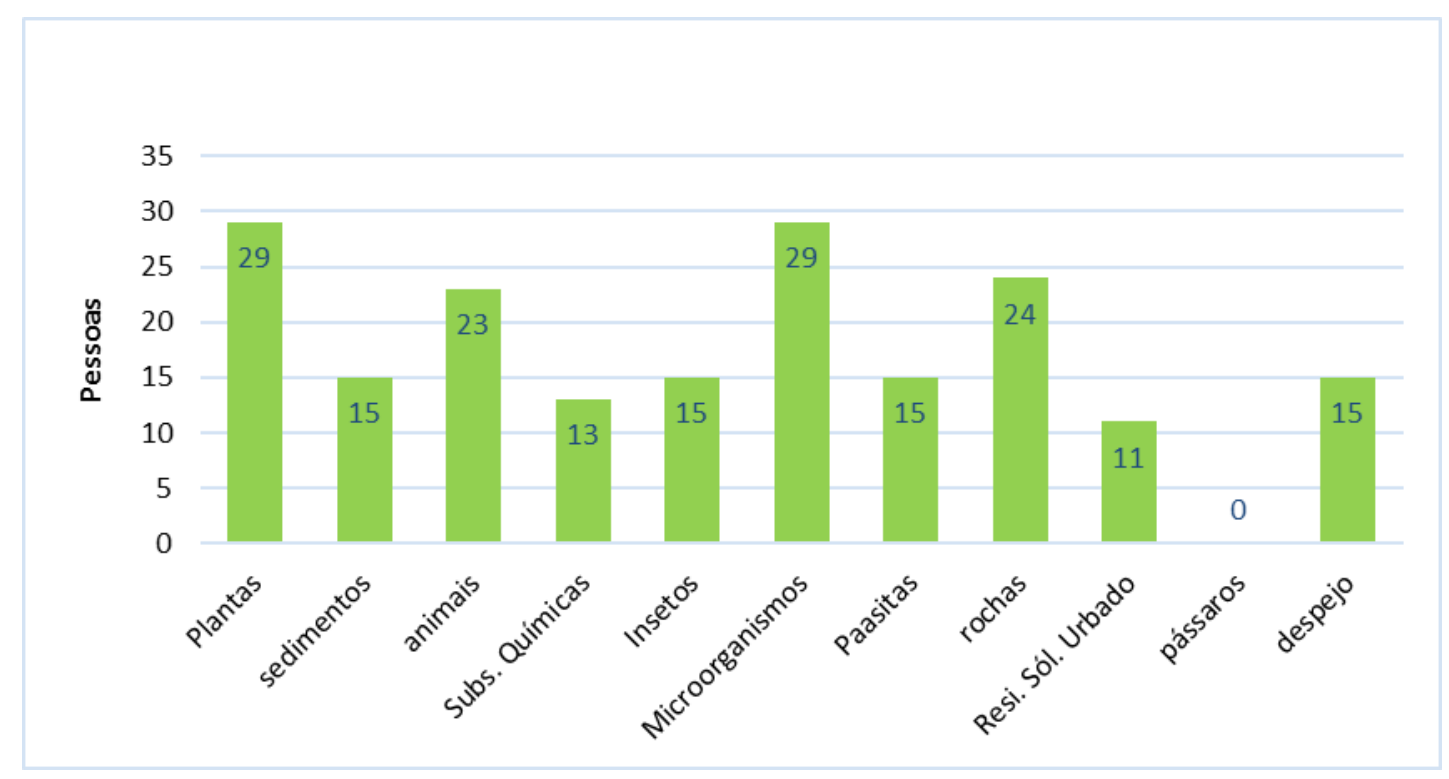

Fonte: Autores, 2013

Ao final da oficina, viu-se que houve um aumento significativo em relação a percepção das crianças, sendo observado principalmente pelo fado de que $96 \%$ das crianças perceberam que existiam sedimentos nos corpos d'água, como mostra a figura 2. 
Figura 2: Resultados da questão 1, "O que você acha que tem nas águas de um rio?", aplicada para os alunos do 60 ano referente ao questionário II

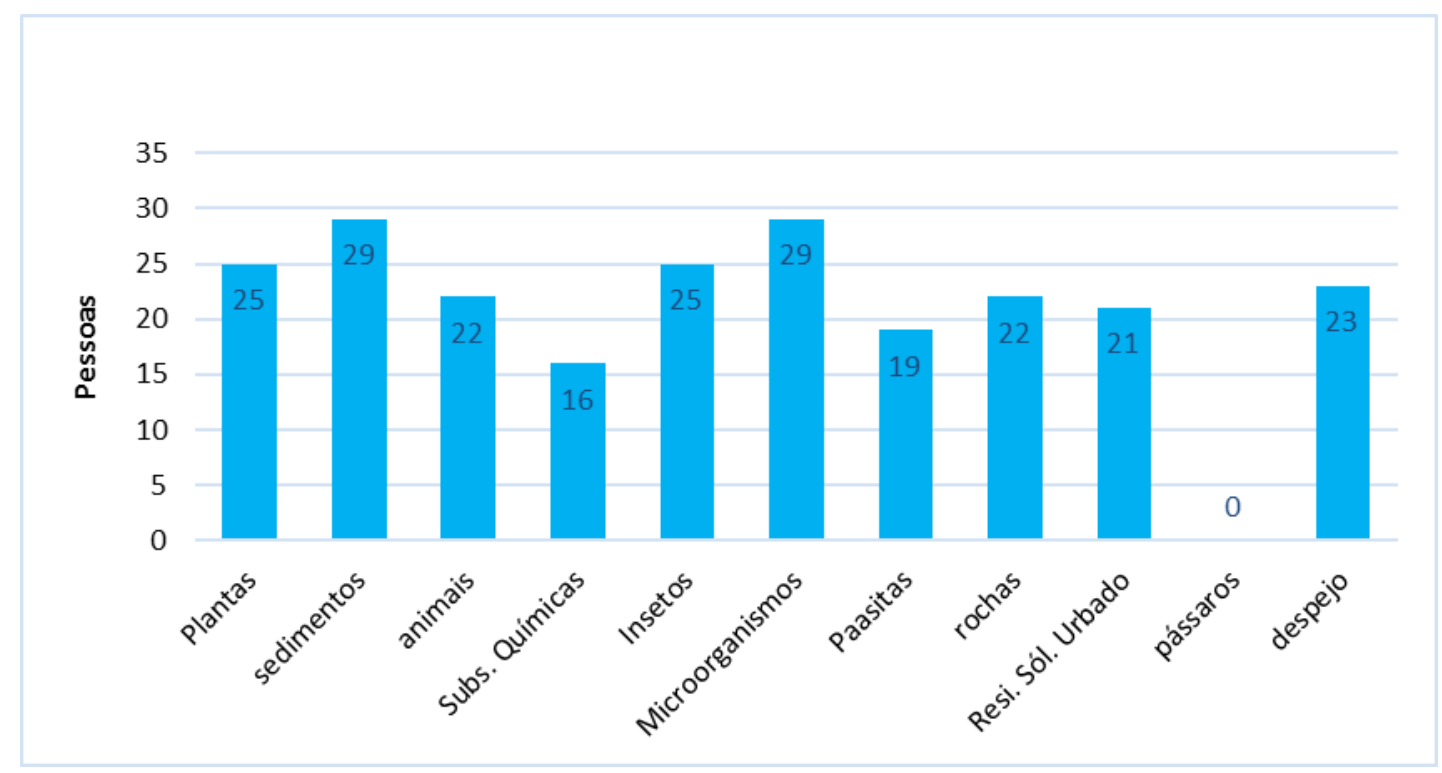

Fonte: Autores, 2013

Nesta mesma questão quase a totalidade dos universitários consideraram que existe plantas, animais, substancias químicas, entre outros em corpos d'água no questionário I. Por isto, no resultado após o campo não houve alterações significativas nesse quadro de respostas, pois os capacitados inicialmente já sabiam o que se encontrava em corpos d'água.

Foi aplicada também uma questão onde se perguntava se os seres vivos e outros componentes presentes nas águas indicam sua qualidade, $26 \%$ dos alunos do ensino fundamental disseram que não, o que é um dado aceitável pelo fato de que anteriormente, $26 \%$ dos mesmos disseram não saber o que é qualidade da água.

Após a parte prática observou-se que $93 \%$ passaram a entender que os seres vivos e os componentes presentes nas águas indicam sua qualidade.

Já para os universitários esta questão teve um resultado controverso, visto que inicialmente $21 \%$ dos mesmos disseram não saber o que é qualidade da água, mas a totalidade disse entender que os seres vivos e componentes presentes na água indicam sua qualidade. 
Pode-se entender isto pensando que a primeira pergunta tenha ficado um pouco ampla, sendo que como a segunda estava mais especificada, possibilitando uma melhor assimilação.

Ao final do campo, como era esperado, o resultado se manteve, com $100 \%$ dos alunos entendendo que os seres vivos e os componentes das águas indicam sua qualidade.

Outra questão foi desenvolvida para analisar a importância que os capacitando atribuem a mata ciliar. $76 \%$ dos alunos do $6 \%$ ano, no questionário I, colocaram que a mata ciliar é importante para prevenção da erosão, $56 \%$ que é importante para a proteção do solo e $7 \%$ que é importante para a alimentação dos animais.

Nenhuma delas colocou que serve como esconderijo de bandido, isso foi atribuído ao fato de isso ser uma crença da população menos instruída, e as crianças capacitadas era da classe social mais favorecida. A quantificação das respostas está contida na figura 3 .

Figura 3: Resultados da questão 2, "Qual a importância da mata ciliar?", aplicada para os alunos do 6ㅇ ano referente ao questionário $I$.

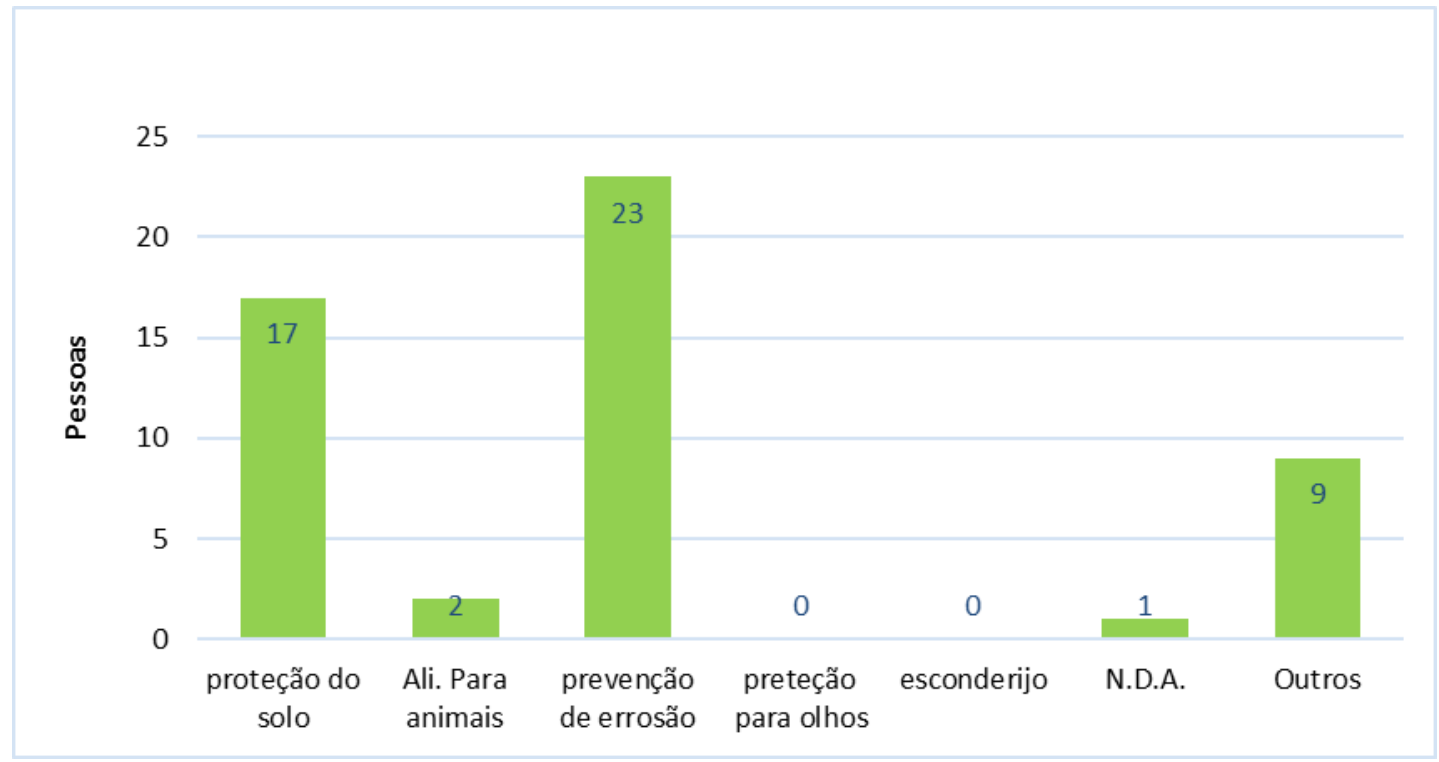

Fonte: Autores, 2013

No questionário $\mathrm{II}$, os alunos do $6^{\circ}$ ano apresentaram uma melhora no entendimento da importância da mata ciliar. Foi observado que $97 \%$ colocaram que a 
mata ciliar é importante para prevenção da erosão, 73\% disseram que é importante para a proteção do solo e 37\% que é importante para a alimentação dos animais.

Tais dados estão contidos na figura 4. Estes resultados mostram que a mesma quantidade de pessoas que entenderam que a mata ciliar serve para a proteção do solo, também entenderam que a mesma serve para se prevenir erosões. Isso mostra o quanto o projeto melhorou no entendimento dos alunos em relação à importância de uma mata ciliar para os diversos aspectos.

Figura 4: Resultados da questão 2, "Qual a importância da mata ciliar?", aplicada para os alunos do 60 ano referente ao questionário II.

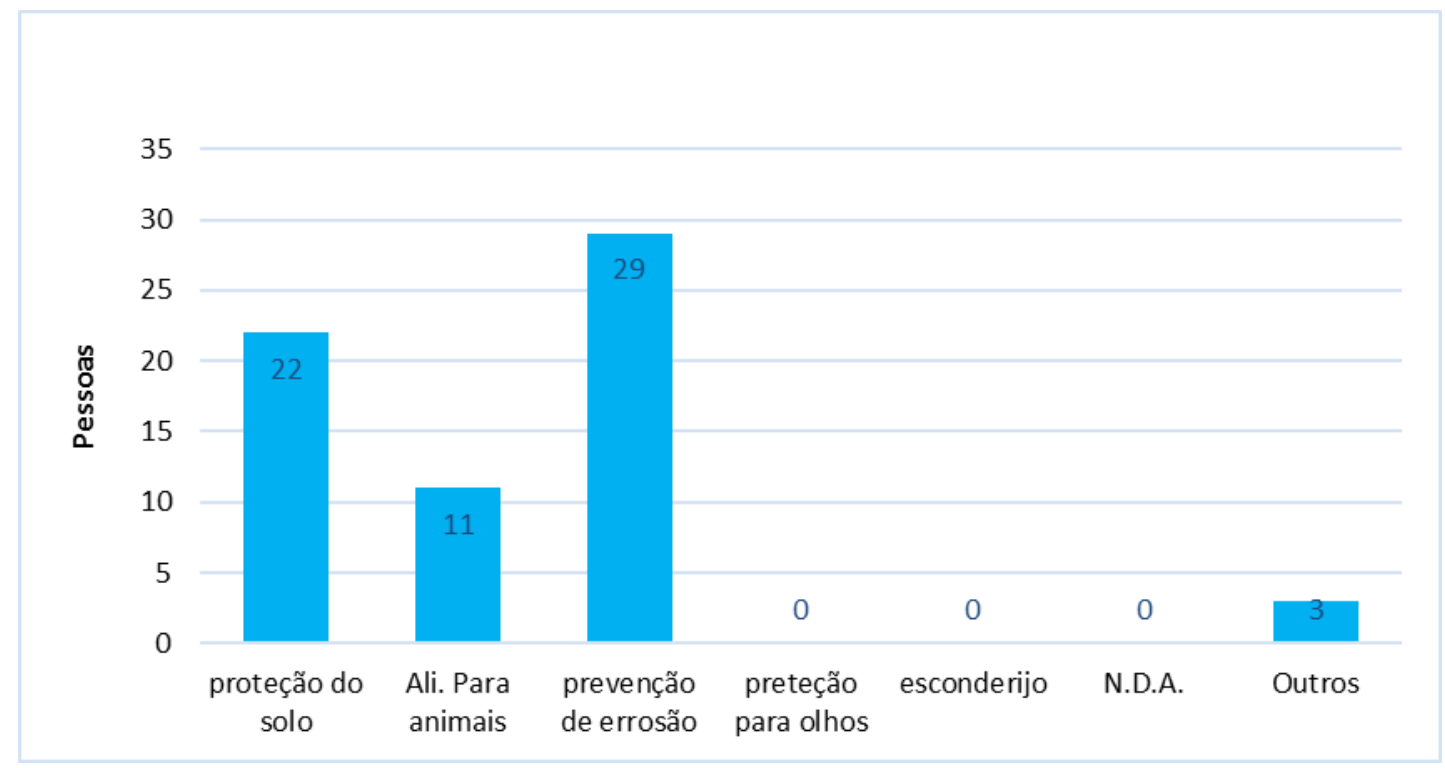

Fonte: Autores, 2013

Na mesma questão, a totalidade dos alunos de graduação, no questionário I, colocou que a mata ciliar é importante para proteção do solo e prevenção da erosão e $50 \%$ colocaram que é importante para alimentação dos animais.

Um dos alunos colocou que servia como esconderijo de bandido, atribuímos isso a crença popular de que lugares com mata servem para este fim. A quantificação das respostas do questionário I é mostrada na figura 5. 
Figura 5: Resultados da questão 2, "Qual a importância da mata ciliar?", aplicada para os alunos de graduação referente ao questionário $\mathrm{I}$.

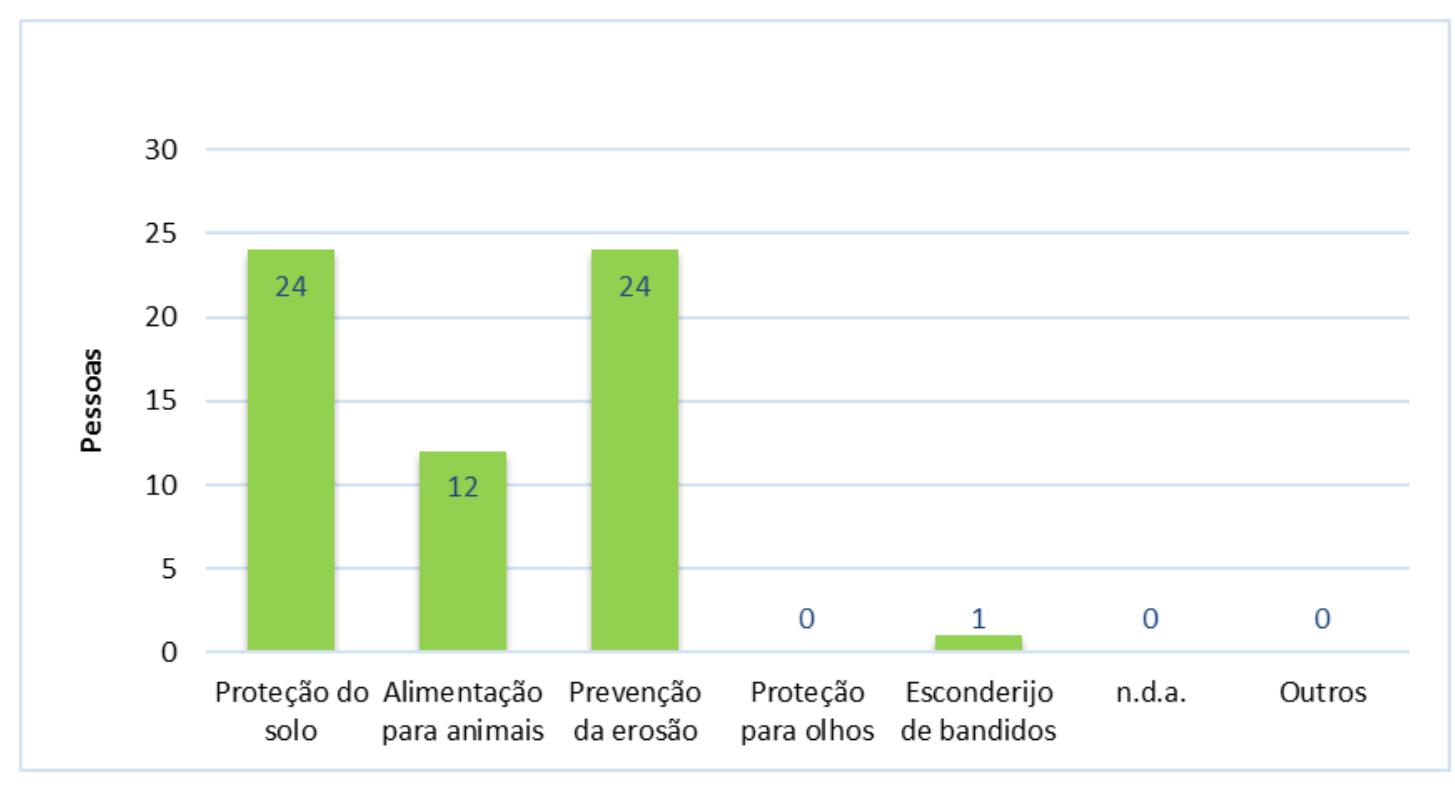

Fonte: Autores, 2013

Com o questionário II analisou-se as respostas dos alunos de graduação após a parte prática da oficina. A quantificação das respostas é mostrada na figura 6.

Figura 6: Resultados da questão 2, "Qual a importância da mata ciliar?", aplicada para os alunos de graduação referente ao questionário II.

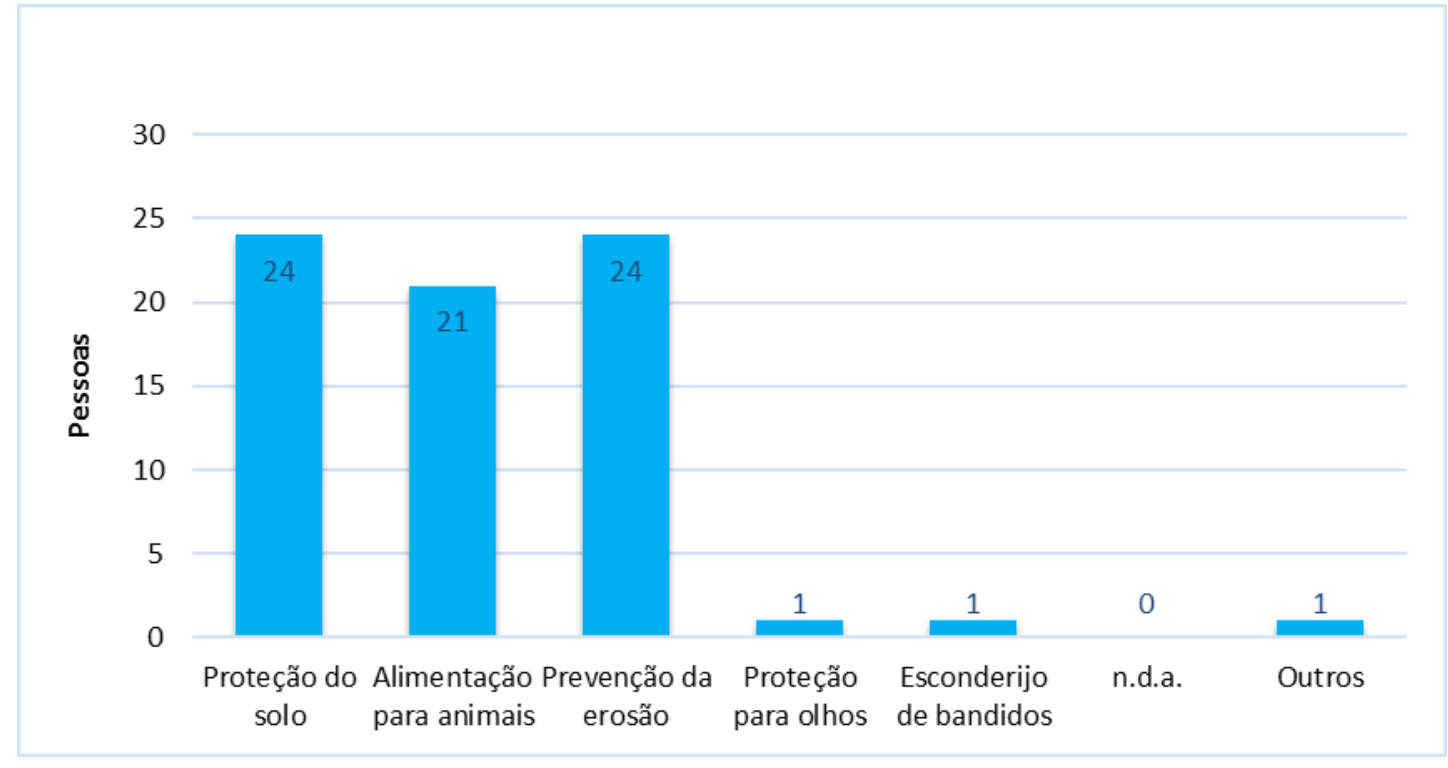

Fonte: Autores, 2013 
Neste questionário todos os alunos colocaram novamente a importância para a proteção do solo e prevenção da erosão e um que servia para esconderijo de bandido.

O percentual da opção de alimentação para animais aumentou para aproximadamente $88 \%$, o que indica que a ida a campo demonstrou que os mesmos estavam certos em relacionar a mata ciliar com o solo, e aumentou suas percepções em relação à alimentação para animais.

Entretanto, uma pessoa marcou que ela também serve de proteção para os olhos, acredita-se que, pelo fato de que estava um tempo ensolarado no dia da parte prática, esta pessoa acreditou ser plausível assinalar esta questão.

\section{CONCLUSÃO}

Pôde-se concluir que a metodologia de educação ambiental utilizada foi eficiente, visto que a percepção ambiental tanto dos alunos do sexto ano, quanto dos universitários aumentou.

Ainda é possível perceber que ao final houve uma maior porcentagem de universitários apresentando as respostas esperadas, mas a diferença desta porcentagem para as crianças não foi muito grande, levando principalmente em consideração que os alunos do sexto ano se encontram em uma classe social mais favorecida do que os alunos de graduação.

Considerando os conhecimentos iniciais de ambos os grupos, percebe-se que, apesar de a porcentagem das respostas dos universitários terem sido maior do que de crianças, houve um maior aumento da percepção nas crianças. Atribuímos isso ao fato de as crianças terem um menor conhecimento inicial que os universitários.

Assim, observando que os conceitos apresentados são básicos, os adolescentes, em geral, já conheciam uma grande parte deles. Portanto, o aumento no conhecimento deles foi menor quando comparado com o das crianças. 
Como houve um aumento da percepção de ambos os grupos, e pelo fato de eles se encontrarem em diferentes faixas etárias, o projeto se mostrou eficaz para atuar tanto para crianças quanto universitários, sendo mais eficiente para crianças.

\section{REFERÊNCIAS}

ALVES, E.C. Monitoramento da qualidade da água da Bacia do Rio Pirapó. 2006. 105p. Dissertação (Mestrado em Engenharia Química) - Departamento de Engenharia Química. Universidade Estadual de Maringá, Maringá

BRANDALISE, L.T. et al. A percepção e o comportamento ambiental dos universitários em relação ao grau de educação ambiental. Gest. Prod., São Carlos, v. 16, n. 2, p. 273-285, jun. 2009.

BRASIL. Lei n 9.795, de 27 de abril de 1999. Dispõe sobre a educação ambiental, institui a Política Nacional de Educação Ambiental e dá outras providências. Diário Oficial da União (D.O.U.), Brasília, 28/4/1999. Disponível em:<http://www.planalto.gov.br/ccivil_03/leis//9795.htm>. Acesso em: 26 mai. 2014.

DIAS, G.F. Educação ambiental: princípios e práticas. 7. ed. São Paulo: Gaia, 2001

FREIRE, R. Monitoramento da qualidade da água da bacia hidrográfica do Ribeirão Maringá. 175 p. Dissertação (Mestrado em Engenharia Química) - Universidade Estadual de Maringá, Maringá, 2010.

LIMA, G.C. Questão ambiental e educação: contribuições para o debate. Ambiente \& Sociedade, Campinas, v. 2, n. 5, p. 135-153, dez. 1999.

MEDEIROS, H. et al. Revista Brasileira de Educação Ambiental. Brasília: Rede Brasileira de Educação Ambiental, 2004.

MELAZO, G.C. Percepção ambiental e educação ambiental: uma reflexão sobre as relações interpessoais e ambientais no espaço urbano. Olhares \& Trilhas, Uberlândia, v. 1, n. 6, p. 45-51, jun. 2005.

POSSAMAI, O. A percepção e o comportamento ambiental dos universitários em relação ao grau de educação ambiental. Gestão \& Produção, São Carlos, v. 16, n. 2, p. 273-285, jul. 2009.

RUSCHEINSKY, A. Educação ambiental: abordagens múltiplas. Porto Alegre: Artmed, 2002.

SAUVÉ, L. Educação ambiental: possibilidades e limites. Educação e pesquisa, v. 31, n. 2, p. 317322. São Paulo, ago. 2005. 